\title{
Prevalence of Campylobacter jejuni and Campylobacter coli among broilers in Bareilly region
}

\author{
Hina Malik¹, Ashok Kumar¹, S. Rajagunalan¹, J. L. Kataria ${ }^{1}$, Anjay $^{1}$ and Swati Sachan ${ }^{2}$
}

1. Division of Veterinary Public Health, Indian Veterinary Research Institute (IVRI), Izatnagar, Uttar Pradesh, India; 2. Immunology Section, Indian Veterinary Research Institute (IVRI), Izatnagar, Uttar Pradesh, India. Corresponding author: Hina Malik, e-mail: hinaiqbal@rediffmail.com, AK: ashokakt@rediffmail.com, SR: drgunavet@gmail.com, JLK: jluvjkat@gmail.com, A: dranjayvet@gmail.com, SS: swatischan@gmail.com Received: 20-06-2014, Revised: 28-08-2014, Accepted: 04-09-2014, Published online: 09-10-2014

doi: 10.14202/vetworld.2014.784-787. How to cite this article: Malik H, Kumar A, Rajagunalan S, Kataria JL, Anjay, Sachan S (2014) Prevalence of Campylobacter jejuni and Campylobacter coli among broilers in Bareilly region, Veterinary World 7(10): 784-787.

\begin{abstract}
Aim: To determine the prevalence of Campylobacter jejuni and Campylobacter coli among broilers at the time of slaughter in and around Bareilly, India.

Materials and Methods: A total of 100 chicken caecal samples were screened by conventional plating in modified charcoal cefoperazone deoxycholate agar with incubation at $42^{\circ} \mathrm{C}$ for $48 \mathrm{~h}$ under microaerophilic conditions. The characteristic colonies were confirmed by morphological and biochemical characteristics and multiplex polymerase chain reaction (mPCR) assay targeting lpxA gene.

Results: Out of 100 chicken caecal samples, 32 yielded isolates with typical phenotypic of Campylobacter species. The hippurate hydrolysis test found to be positive for 2 isolates, categorized as C. jejuni and negative for 30 isolates. The mPCR assay targeting lpxA gene also confirmed 2 (6.25\%) isolates as C. jejuni, and 30 (93.75\%) isolates as C. coli.

Conclusion: The present study showed broilers to an important source of Campylobacter in the region with predominance of C. coli than C. jejuni indicating a shift in the prevalence of important species of Campylobacter. To understand the variation in pattern of occurrence of species with high prevalence of organisms, detail studies on the ecology of campylobacteriosis are suggested.
\end{abstract}

Keywords: Campylobacter coli, Campylobacter jejuni, multiplex polymerase chain reaction, lpxA gene.

\section{Introduction}

Campylobacters are gram-negative, spiral, catalase, oxidase and indoxyl acetate positive bacteria with cork screw motility. The genus Campylobacter comprises of 25 species, 8 subspecies and 2 provisional species [1]. Thermophilic campylobacters are known to cause gastroenteritis in human worldwide, with major involvement of Campylobacter jejuni and Campylobacter coli. Earlier reports suggest that the campylobacteriosis accounts for 5-15\% of all illnesses worldwide [2].

It has been reported to occur more frequently than infections caused by Salmonella spp., Shigella spp., or Escherichia coli O157:H7 [3]. In 2012, annual incidence rate of the disease was reported as 4.4-9.3 per 1000 human population [4]. The $14 \%$ increase was observed in the incidence rate from 2006 to 2012, and 2011 was declared as the year with the highest incidence for campylobacteriosis [5]. A 4.5\% incidence rate of the disease was observed in the southern part of India, with the majority of the infections by C. jejuni along with few $C$. coli and mixed infection with both the species [6]. Several workers have reported Campylobacter infection in $10.28-13.5 \%$ of diarrheic

Copyright: The authors. This article is an open access article licensed under the terms of the Creative Commons Attributin License (http:// creative commons.org/licenses/by/2.0) which permits unrestricted use, distribution and reproduction in any medium, provided the work is properly cited. cases from North India $[7,8]$. This disease is characterized by diarrhea, fever and abdominal cramps. The disease is generally self-limiting but may sometimes leave behind debilitating sequelae with complications like reactive arthritis and Guillain-Barre' syndrome, a neuropathological disorder characterized by acute ascending bilateral paralysis [9]. Poultry has been recognized as the primary reservoir of Campylobacter spp. thus, most of the infections are acquired by the consumption and handling of contaminated poultry.

Keeping this in view, the present study was undertaken to determine the prevalence of $C$. jejuni and C. coli among broilers at the time of slaughter in Bareilly, India.

\section{Materials and Methods}

\section{Sampling procedures}

A total of 100 broiler caecal samples were collected from retail meat shops (37) and slaughter houses (63) in sterile containers and transported immediately to the laboratory under cold conditions. The samples were processed without any delay to ensure that the organisms remain viable and culturable.

\section{I solation and identification of Campylobacter}

The caecal contents were scraped with the help of sterile inoculation loop and streaked directly onto modified charcoal cefoperazone deoxycholate agar (mCCDA) plates and incubated under microaerophilic conditions (BD GasPak ${ }^{\mathrm{TM}} \mathrm{EZ}$, USA) at $42^{\circ} \mathrm{C}$ for 
$48 \mathrm{~h}$. The plates were observed for the development of characteristic colonies and one characteristic colony from each plate was sub cultured and examined for phenotypic characteristics by Gram's staining, motility, oxidase, catalase and hippurate hydrolysis tests.

\section{Molecular confirmation}

A multiplex polymerase chain reaction (mPCR) assay targeting the lipid gene 'IpxA' was used for confirmation of Campylobacter at species level as per the method described by Klena et al. [10] with slight modifications. In this modified mPCR assay two species of thermophilic campylobacters viz. C. jejuni and $C$. coli were targeted. The mPCR was performed in a total reaction volume of $25 \mu \mathrm{l}$ containing $2.5 \mu \mathrm{l}$ of 10X dream Taq buffer, $2.5 \mu \mathrm{l}$ of $2 \mathrm{mM}$ of each dNTP, 15 pmol of each primer (Table-1), 1 U dream Taq polymerase, $2 \mu \mathrm{l}$ of bacterial DNA template extracted using DNeasy blood and tissue kit (Qiagen, Germany) and nuclease-free water up to $25 \mu \mathrm{l}$. The mPCR amplification was performed in a thermal cycler (Eppendorf, Germany) with initial denaturation at $95^{\circ} \mathrm{C}$ for $5 \mathrm{~min}$, followed by 30 cycles of denaturation at $94^{\circ} \mathrm{C}$ for $30 \mathrm{~s}$, annealing at $50^{\circ} \mathrm{C}$ for $30 \mathrm{~s}$ and extension at $72^{\circ} \mathrm{C}$ for $1 \mathrm{~min}$. Final extension was carried out at $72^{\circ} \mathrm{C}$ for $10 \mathrm{~min}$. The amplified products were electrophoresed in 2.0\% agarose gel (SRL, India) stained with ethidium bromide $(0.5 \mu \mathrm{g} / \mathrm{ml})$ and image was documented (Figure-1) in a gel documentation system (UVP, USA).

\section{Results and Discussion}

Out of 100 broiler caecal samples screened for the presence of Campylobacter using mCCDA plating, and identified by morphological and biochemical tests, viz.: oxidase, catalase and indoxyl acetate hydrolysis tests and $\mathrm{H}_{2} \mathrm{~S}$ production in triple sugar iron slant, 32 samples were found positive. Further, all the isolates were subjected to hippurate hydrolysis test to identify C. jejuni (hippurate hydrolysis positive), in which only two isolates were identified as $C$. jejuni while the remaining 30 isolates negative for hippurate hydrolysis were considered as other Campylobacter species.

The isolates were then subjected to mPCR assay in which out of 32 isolates, two were identified as $C$. jejuni and the remaining 30 isolates were identified as $C$. coli based on the production of species specific amplicons 331 bp and 391 bp respectively. These findings revealed that the MPCR based assay was in accordance with hippurate hydrolysis test for species level identification of campylobacters.
The finding of the present study showed 32\% overall prevalence of thermophilic campylobacters among broilers, which is in accordance with the previous report from Bareilly regions [11]. However, earlier workers from this region have reported a comparatively lower prevalence of Campylobacter in poultry, viz. $14.28 \%$ [12], 15.48\% [13], 18\% [14], $20 \%$ [15], 21.8\% [16] and in contrast to these reports a much higher prevalence (65\%) of Campylobacter in chicken caecum was also reported [17].

This study showed that $C$. coli were prevalent in 93.75\% (30/32) and C. jejuni in 6.25\% (2/32) among broilers slaughtered at chicken shop which was in concordance with the finding of other workers at Pantnagar and Bareilly regions $[13,18]$. Similar findings were also reported by other workers [19-22]. In contrast to the findings of the present study, many of the workers reported a higher prevalence of $C$. jejuni in poultry than C. coli $[6,23-27]$. The reason for this difference in prevalence rates of $C$. jejuni and C. coli among poultry is unknown; however, impact of differences in the isolation procedures and geographic differences has been suggested [21]. Modifications in poultry breeding conditions, use of growth promoters,

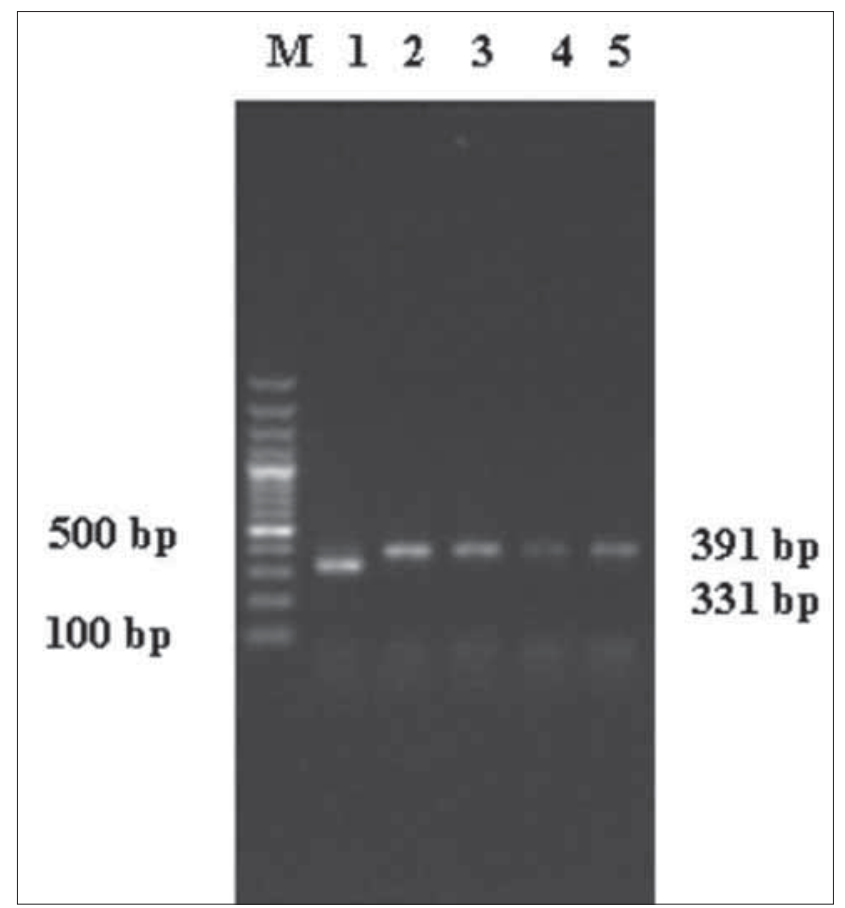

Figure-1: Electrophoresis of IpxA gene mPCR products on 2.0\% agarose. Lane M: 100 bp DNA ladder, Lane 1 and 2: Positive controls, Lane 3-5: Samples with positive amplicon. http://apps. who.int/iris/bitstream/10665/80751 /1/9789241564601_eng.pdf. $14 \%$ increase http://www. cdc.gov/foodnet/PDF̄s/ncezid-trends-factsheet-508c. pdf.

Table-1: Details of oligonucleotide primers used for MPCR.

\begin{tabular}{llccc}
\hline Primers & Sequence (5'-3') & Product size & Target gene & References \\
\hline mP-Cj & F: ACAACTTGGTGACGATGTTGTA & $331 \mathrm{bp}$ & IpxA & [9] \\
mP-Cc & F: AGACAAATAAGAGAGAATCAG & $391 \mathrm{bp}$ & & \\
$\mathrm{mP}-\mathrm{R}$ & R: CAATCATGDGCDATATGASAATAHGCCAT & & & \\
\hline
\end{tabular}

$\mathrm{mPCR}=$ Multiplex polymerase chain reaction 
and increased antimicrobial resistance in $C$. coli can be some of the reasons [19].

\section{Conclusion}

It may be concluded from the present study that thermophilic campylobacters are highly prevalent in the broilers slaughtered in Bareilly region. The high level of presence of $C$. coli than $C$. jejuni may be due to laboratory practice and ecological discrepancies including variation in antibiotic resistance, changes in breeding and feeding practices of poultry. However, it has again been observed that the broilers may serve as a prime source of human campylobacteriosis, presently with predominance of $C$. coli infection; therefore, the work on epidemiology of campylobacteriosis is suggested to be continued.

\section{Authors' Contributions}

HM, AK and SR designed the work plan; HM conducted experiments under supervision of AK and SR. Anjay, JLK, SS and SR helped in laboratory processing of samples. All authors contributed in drafting and revision of the manuscript. All authors read and approved the final manuscript.

\section{Acknowledgments}

The authors are thankful to the Director, Indian Veterinary Research Institute, Izatnagar, U.P., for providing the facilities under the project fund entitled "Outreach Programme on Zoonotic Diseases" for this work.

\section{Competing I nterests}

The authors declare that they have no competing interests.

\section{References}

1. Man, S.M. (2011) The clinical importance of emerging Campylobacter species. Nat. Rev. Gastroenterol. Hepatol., 8: 669-685.

2. Adak, G.K., Meakins, S.M., Yip, H., Lopman, B.A. and O’Brien, S.J. (2005) Disease risks from foods, England and Wales, 1996-2000. Emerg. Infect. Dis., 11: 3.

3. CDC. (2008) Division of Food-Borne, Bacterial and Mycotic Diseases (DFBMD) Listing. Centers for Disease Control and Prevention, United States.

4. World Health Organization. (2012) The global view of campylobacteriosis: report of expert consultation, Utrecht, Netherlands, 9 to 11 July 2012. World Health Organization, Geneva, Switzerland.

5. CDC. (2012) Available from: http://www.foodsafetynews. com/2013/04/campylobacter-and-vibrio-rates-rose-in 2012-cdc-progress-report/\#.UpYMqcEhhhk. Last accessed on 25-11-2013.

6. Rajendran, S., Babji, P., George, A.T., Rajan, D.P., Kang, G. and Ajjampur, S.S. (2012) Detection and species identification of Campylobacter in stool samples of children and animals from Vellore, south India. Indian J. Med. Microbiol., 30: 85-88.

7. Ghosh, R., Uppal, B., Aggarwal, P., Chakravarti, A. and Jha, A.K. (2013) Increasing antimicrobial resistance of Campylobacter jejuni isolated from paediatric diarrhea cases in a tertiary care hospital of New Delhi, India. J. Clin. Diagn. Res., 7: 247.
8. Jain, D., Sinha, S., Prasad, K.N. and Pandey, C.M. (2005) Campylobacter species and drug resistance in a North Indian rural community. Trans. R. Soc. Trop. Med. Hyg., 99: 207-214.

9. Yuki, N., Susuki, K., Koga, M., Nishimoto, Y., Odaka, M., Hirata, K. and Yamada, M. (2004) Carbohydrate mimicry between human ganglioside GM1 and Campylobacter jejuni lipooligosaccharide causes Guillain-Barré syndrome. Proc. Natl. Acad. Sci., 101: 11404-11409.

10. Klena, J.D., Parker, C.T., Knibb, K., Ibbitt, J.C., Devane, P.M.L., Horn, S.T., Miller, W.G. and Konkel, M.E. (2004) Differentiation of Campylobacter coli, Campylobacter jejuni, Campylobacter lari and Campylobacter upsaliensis by a multiplex PCR developed from the nucleotide sequence of the lipid A gene IpxA. J. Clin. Microbiol., 42: 5549-5557.

11. Garbyal, S.S. (2000) Studies on thermophilic campylobacters isolated from man and foods of animals origin. MVSc Thesis Submitted to Deemed University, Indian Veterinary Research Institute, Izatnagar, India.

12. Singh, H.D. (2006) Isolation and PCR-based detection of Campylobacter jejuni and Campylobacter fetus in man, animals and foods of animal origin. MVSc Thesis Submitted to Deemed University, Indian Veterinary Research Institute, Izatnagar, India.

13. Rajagunalan, S. (2010) Isolation, PCR based detection and FLA typing of thermophilic Campylobacters. MVSc Thesis Submitted to G.B.P.U.A\&T., Pantnagar, India.

14. Kumar, S.M. (2011) Studies on molecular heterogeneity of thermophilic Campylobacter isolates from man and animals. MVSc Thesis Submitted to Deemed University, Indian Veterinary Research Institute, Izatnagar, India.

15. Khan, I.A. and Khanna, P.N. (1992) Occurrence of thermophilic Campylobacter of public health importance in animals, birds and food. Proceedings of $3^{\text {rd }}$ World Congress. Foodborne Infection and Intoxication, Berlin. p462-467.

16. Sharma, A.K. (2004) Detection of zoonotic Campylobacter species in animals, human beings and foods. MVSc Thesis Submitted to Deemed University, Indian Veterinary Research Institute, Izatnagar, India.

17. Khan, I.A. (1989) Occurrence of thermophilic Campylobacter of public health importance in animals, birds and food. MVSc Thesis Submitted to Deemed University, Indian Veterinary Research Institute, Izatnagar, India.

18. Prasanna, K.V. (2013) Isolation and molecular characterization of Campylobacter jejuni and Campylobacter coli from human and poultry caeca as well as meat. MVSc Thesis Submitted to G.B.P.U.A \&T., Pantnagar, India.

19. Desmonts, M.H., Dufour-Gesbert, F., Avrain, L. and Kempf, I. (2004) Antimicrobial resistance in Campylobacter strains isolated from French broilers before and after antimicrobial growth promoter bans. J. Antimicrob. Chemother., 54: 1025-1030.

20. Padungtod, P. and Kaneene J.B. (2005) Campylobacter in food animals and humans in northern Thailand. J. Food Prot., 68: 2519-2526.

21. Zorman, T., Heyndrickx M., Uzunovic-Kamberovic S. and Mozina S. (2006) Genotyping of Campylobacter coli and C. jejuni from retail chicken meat and humans with campylobacteriosis in Slovenia and Bosnia and Herzegovina. Int. J. Food Microbiol., 110: 24-33.

22. Henry, I., Reichardt, J., Denis, M. and Cardinale, E. (2011) Prevalence and risk factors for Campylobacter spp. in chicken broiler flocks in reunion Island (Indian Ocean). Prev. Vet. Med., 100: 64-70.

23. Chowdhary, S., Balakrish, N.G. and Pal, S.C. (1984) Occurrence of Campylobacter jejuni in country chicken in Calcutta. Indian J. Med. Res., 79: 171-173.

24. Harvey, R.B., Young, C.R., Ziprin, R.L., Hume, M.E., Genovese, K.J., Anderson, R.C., Droleskey, R.E., Stanker, L.H. and Nisbet, D.J. (1999) Prevalence of 
Campylobacter species isolated from the intestinal tract of pigs raised in an integrated swine production system. J. Am. Vet. Med. Assoc., 215: 1601-1604.

25. Saleha, A.A. (2002) Isolation and characterization of Campylobacter jejuni from broiler chickens in Malaysia. Int. J. Poult. Sci., 1: 94-97.

26. Mena, C., Rodrigues, D., Silva, J., Gibbs, P. and Teixeira, P. (2008) Occurrence, identification, and characterization of
Campylobacter species isolated from Portuguese poultry samples collected from retail establishments. Poult. Sci., 87: 187-190.

27. Deckert, A., Valdivieso-Garcia, A., Reid-Smith, R., Tamblyn, S., Seliske, P., Irwin, R., Dewey, C., Boerlin, P. and McEwen, S.A. (2010) Prevalence and antimicrobial resistance in Campylobacter spp. isolated from retail chicken in two health units in Ontario. J. Food Prot., 73: 1317-24.

$* * * * * * * *$ 